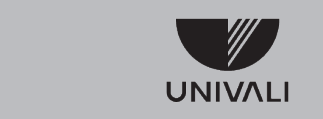

UNIVERSIDADE DO VALE DO ITAJAí

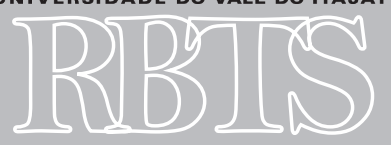

Revista Brasileira de Tecnologias Sociais
1 PPGA/MPA, Universidade Federal Fluminense, julioabreu@ vm.uff.br

2 Graduando em Administração, Universidade Federal Fluminense, lucastibirica@gmail.com
Revista Brasileira de Teonologias Sociais, v.4, n.2, 2017

doi: $10.14210 /$ rbts vatn2.p135-148

\section{TECNOLOGIA SOCIAL COMO MECANISMO \\ DE EMANCIPAÇÃO SOCIAL? \\ UMA ANÁLISE EMPÍRICA}

\section{SOCIAL TECHNOLOGY AS A MECHANISM \\ FOR SOCIAL EMANCIPATION? A \\ N EMPIRICAL ANALYSIS}

\author{
Júlio Cesar Andrade de Abreu ${ }^{1}$ \\ Lucas Villanacci Tibiriçáa
}

RESUMO: Este texto ensaístico busca reflexionar sobre o constructo da Tecnologia Social como mecanismo de emancipação social. A análise é baseada em pesquisa bibliográfica e, empiricamente, na experiência do projeto Moradia Urbana com Tecnologia Social no Conjunto Residencial Candelária (Volta Redonda, Rio de Janeiro). Procurou-se observar traços emancipatórios nos discursos dos moradores a partir de entrevistas semiestruturadas e os resultados desse trabalho apontam que houve diferentes impactos decorrentes das reaplicações das Tecnologias Socias na comunidade em questão; apesar de não se fazerem notar mudanças substanciais na vida coletiva do empreendimento habitacional, transformações significativas aconteceram em níveis individuais.

PALAVRAS-CHAVE: Tecnologia Social; Emancipação; Volta Redonda.

ABSTRACT: This essay reflects on the construct of Social Technology as a mechanism for social emancipation. The analysis is based on bibliographic research and, empirically, on the experience of the project Moradia Urbana com Tecnologia Social conducted at Candelária Housing Project in the city of Volta Redonda, Rio de Janeiro. We sought to observe emancipatory traits within the inhabitants' discourses, through semi-structured interviews. The results of this work indicate that there have been difficult impacts of the reapplication of the Social Technologies in the community in question; although no substantial changes have been observed in the collective life of the housing enterprise, significant transformations have occurred in the lives of the individuals.

KEYWORDS: Social Technology; Emancipation; Volta Redonda. 
UNIVALI

UNIVERSIDADE DO VALE DO ITAJAÍ

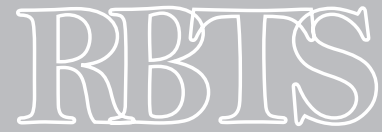

Revista Brasileira de Tecnologias Sociais 


\section{INTRODUÇÃO}

Segundo Feenberg (2001), a tecnologia é uma importante fonte de poder nas sociedades modernas. De acordo com Cupani (2004), conceitos como controle, eficiência e racionalização de recursos são características da tecnologia, o que não permite entendê-la como neutra, haja vista que, estruturalmente, pode possuir valores ideológicos em sua concepção. Denominada por Dagnino (2009) como Tecnologia Convencional (TC), este modelo de tecnologia possui a ideologia capitalista e reforça a alienação da sociedade, limitando a vida humana a uma única dimensão: o mercado. Apesar de hegemônicos, o capitalismo e a TC não são totalizantes, afinal experiências alternativas, em termos de tecnologia, são baseadas em outra lógica, definida como Tecnologia Social (TS) na perspectiva de Dagnino (2009).

Levando em consideração o cenário anteriormente descrito, faz-se aqui o esforço de reflexionar sobre como o constructo da TS pode ser vislumbrado como mecanismo de emancipação social. A análise apresentada nos próximos tópicos tem caráter empírico ao investigar a percepção dos moradores do Conjunto Residencial Candelária (Volta Redonda, Rio de Janeiro) acerca da experiência proposta pelo projeto Moradia Urbana com Tecnologia Social (MUTS). A experimentação de reaplicação de TS no Conjunto Residencial como objeto de investigação permitiu indagar, fundamentado na prática, se é possível falar sobre emancipação social a partir da TS. No caso em questão, abordando temáticas como habitação, educação e geração de renda, a TS é uma ferramenta que possibilita a articulação com diferentes atores, prefeituras, entes públicos, sociedade civil organizada e moradores, objetivando o desenvolvimento social (INTERAÇÃO, 2014).

Além dessa introdução, este artigo está organizado com o primeiro tópico sobre o tema amplo da Tecnologia Social, seguido pela exposição do projeto MUTS. Posteriormente, faz-se uma explanação metodológica e, por fim, a experiência do Conjunto Residencial Candelária é tratada, precedendo à conclusão, que se vale da reflexão dos autores sobre as narrativas coletadas.

\section{TECNOLOGIA SOCIAL E EMANCIPAÇÃO SOCIAL}

O esforço para conceituar Tecnologia Social (TS) deve ser precedido de uma apreensão do que vem a ser a tecnologia, não adjetivada. Segundo Pinto (2005), a técnica é algo imanente à espécie humana, que pode inventar meios artificiais para resolver problemas e a tecnologia, por sua vez, é a ciência da técnica.

Feenberg (2003, p.2) afirma que "a ciência e a tecnologia partem do mesmo tipo de pensamento racional baseado na observação empírica e no conhecimento da causalidade natural, porém a tecnologia não está preocupada com a verdade, mas sim com a utilidade. Onde a ciência busca o saber, a tecnologia busca o controle”. O mesmo autor estrutura sua análise da tecnologia em dois eixos, representados pelo Quadro 1.

O determinismo admite a tecnologia como autônoma e neutra, devendo-se adaptar à tecnologia, considerada força motriz da história. "Os deterministas acreditam que a tecnologia não é controlada humanamente, mas, pelo contrário, que ela controla os humanos, isto é, molda a sociedade às exigências de eficiência e progresso” (FEENBERG, 2003, p.6-7).

Já o instrumentalismo defende que, apesar de neutra, a tecnologia é controlada pelo homem, sendo “[ [...] simplesmente uma ferramenta ou instrumento da espécie humana com o qual nós satisfazemos nossas necessidades" (FEENBERG, 2003, p.7). 
A tecnologia é...

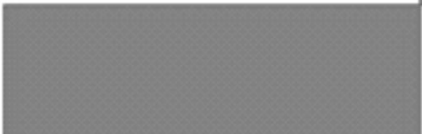

Neutra

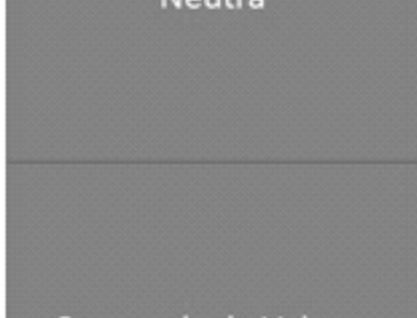

Carregada de Valores

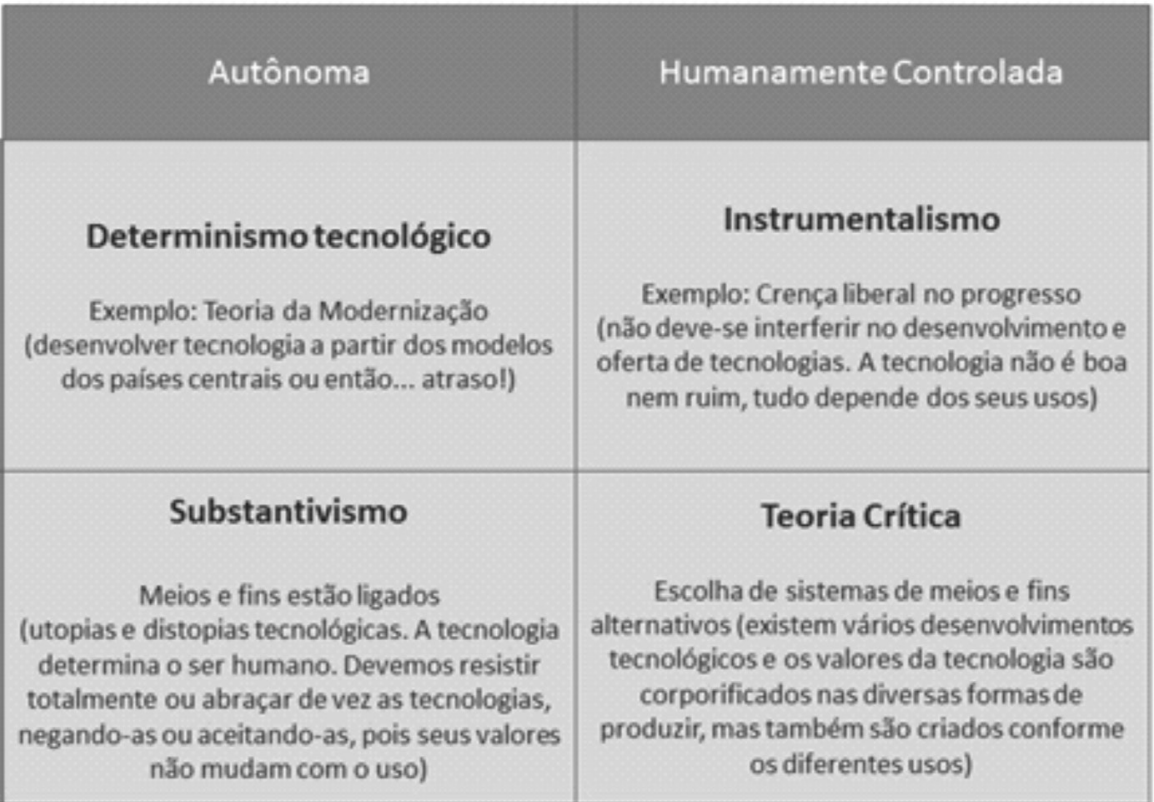

Fonte: Elaborado pelos autores com base em Feenberg (2003).

O substantivismo assume que a tecnologia é carregada de valores e é autônoma. Os valores seriam uma substância, parte inerente ao artefato tecnológico. Segundo Feenberg (2003, p.7), "Se a tecnologia incorpora um valor substantivo, não é meramente instrumental e não pode ser usada segundo diferentes propósitos de indivíduos ou sociedades com ideias diferentes do bem. O uso da tecnologia para esse ou aquele propósito seria uma escolha de valor específica em si mesma”, caracterizando o substantivismo ao assumir que a tecnologia é carregada de valores e autônoma.

Por fim, a Teoria Crítica, sob a ótica de Feenberg (2003, p. 8), “[ [..] reconhece as consequências catastróficas do desenvolvimento tecnológico ressaltadas pelo substantivismo, mas ainda vê uma promessa de maior liberdade na tecnologia”, enxergando-a como humanamente controlada e carregada de valores. Esquematicamente, tem-se:

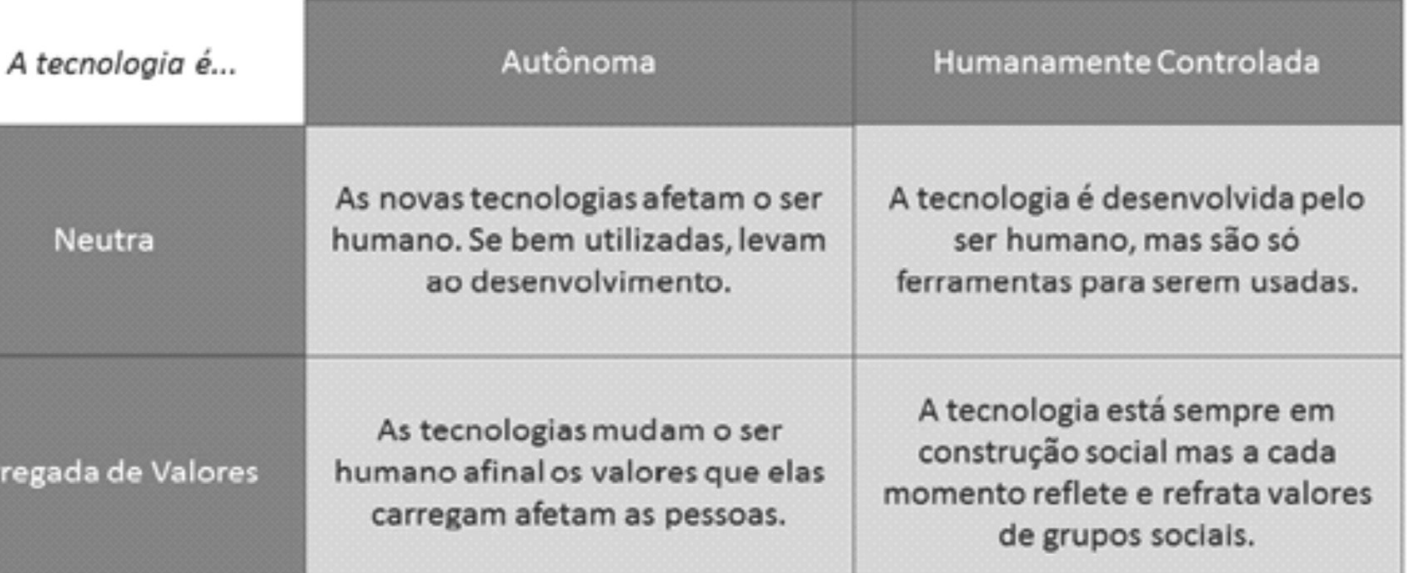

Fonte: Elaborado pelos autores com base em Feenberg (2003).

A chamada Tecnologia Social (TS) pode ser vinculada à perspectiva da Teoria Crítica. Oposta à ideia de Tecnologia Convencional (TC), uma definição frequentemente adotada no Brasil é a da RTS, que entende TS como “produtos, técnicas e/ou metodologias reaplicáveis, desenvolvidas 
na interação com a comunidade e que representem efetivas soluções de transformação social”. De acordo com ITS (2004, p.26), são características da TS: (a) Aprendizagem e participação são processos que caminham juntos: aprender implica participação e envolvimento e participar implica aprender; (b) A transformação social implica compreender a realidade de maneira sistêmica: diversos elementos se combinam por meio de múltiplas relações para construir a realidade; (c) A transformação social ocorre na medida em que há respeito às identidades locais: não é possível haver transformação se não mediante as especificidades da realidade existente; (d) Todo indivíduo é capaz de gerar conhecimento e aprender: a partir do momento que está inserido numa cultura e em contato com o mundo, todo indivíduo produz conhecimento e aprende por meio dessa interação. Ainda corroborando com ITS (2004, p.26), destaca-se como parâmetros da TS:

Razão de ser: visa à solução de demandas sociais concretas, vividas e identificadas pela população. Processos de tomada de decisão: formas democráticas de tomada de decisão, mediante estratégias especialmente dirigidas à mobilização e à participação da população. Papel da população: participação, apropriação e aprendizagem por parte da população e de outros atores envolvidos. Sistemática: planejamento e aplicação de conhecimento de forma organizada. Construção de conhecimentos: produção de novos conhecimentos por meio da prática. Sustentabilidade: visa à sustentabilidade econômica, social e ambiental. Ampliação de escala: gera aprendizagens que servem de referência para novas experiências; gera, permanentemente, as condições favoráveis que tornaram possível a elaboração das soluções, de forma a aperfeiçoá-las e multiplicá-las.

Finalmente, a emancipação social, principal eixo da reflexão proposta adiante, pode ser compreendida como movimento oposto à alienação. Em Marx (1983), o conceito de alienação envolve a relação do trabalhador com o produto de seu trabalho, e ainda com o ser genérico, com outro trabalho e, finalmente, consigo mesmo. Entende-se que a partir da percepção sobre as contradições dialéticas do contexto onde vive, pensando criticamente sua condição humana, o indivíduo se constitui como autônomo orientado por um processo de transformação social. A emancipação social também se relaciona diretamente com a capacidade humana de desvelar e exercer sua expressividade, posicionando-se como sujeito histórico. Aproxima-se da ideia de “atualização humana”, empregada por Guerreiro Ramos (1989).

\section{O PROJETO MORADIA URBANA COM TECNOLOGIA SOCIAL}

Há dois anos, no início de 2015, iniciou-se o projeto MUTS, idealizado pela Fundação Banco do Brasil (FBB) em parceria com a INTERAÇÃO. Segundo site do projeto, a intenção é conciliar a ocupação do espaço urbano com a consciência do ser e estar local, como um estímulo ao espírito público e ao fortalecimento do vínculo entre famílias vizinhas, instigando princípios de associativismo e participação, empoderando a comunidade.

Aplicado nos empreendimentos habitacionais do Programa Nacional de Habitação Urbana, o projeto "é uma ferramenta que possibilita a articulação com diferentes atores, prefeituras, entes públicos, sociedade civil organizada e moradores, objetivando o desenvolvimento social a partir de ações complementares, por meio de tecnologias sociais” (INTERAÇÃO, 2014, s/p), potencializando os efeitos do trabalho social do Minha Casa, Minha Vida. São objetivos do projeto: 
1) Capacitar moradores dos empreendimentos em mobilização social, utilizando tecnologias sociais de metodologia organizativa; 2) Articular e reaplicar uma segunda TS, definida dentro de um portfólio, escolhida pela comunidade; 3) Capacitar as pessoas de referência das famílias em educação financeira; 4) Criar Grupo de Acompanhamento das ações com os representantes do empreendimento, da Instituição Local contratada, do município e do Banco do Brasil. (INTERAÇÃO, 2014, s/p).

Ainda de acordo com o site do projeto (INTERAÇÃO, 2014), a FBB identificou no Banco de Tecnologias Sociais possíveis TS para serem reaplicadas nos empreendimentos habitacionais, estruturando-as em duas etapas. A primeira TS a ser experienciada em todas comunidades beneficiadas pelo projeto é a Transformando Realidades, por meio da Mobilização e Organização Comunitária, desenvolvida pela Rede Internacional de Ação Comunitária - INTERAÇÃO, baseada em dispositivos da instituição internacional Slum Dwellers International, representando-a no Brasil. Na segunda fase do projeto, quatro TS foram escolhidas para serem disponibilizadas para reaplicação, como continuidade da primeira TS; são elas: Criação de Bibliotecas Comunitárias - VAGA LUME; Gestão Comunitária de Resíduos Orgânicos e Agricultura Urbana - CEPAGRO; Produção Agroecológica de Alimentos em Meio Urbano: Hortas Urbanas - Instituto PÓLIS; e Joias Sustentáveis na Ilha das Flores - Redecriar.

Durante o processo de reaplicação da primeira TS, os moradores dos complexos habitacionais escolhem outra TS, uma dentre as quatro opções citadas, a fim de desenvolver ações de consolidação da organização comunitária. Tais ações desenvolvidas nos empreendimentos são acompanhadas por um Grupo de Acompanhamento Local composto por representantes do Banco do Brasil, poder público local, instituições contratadas para a reaplicação das TS e, claro, moradores. Segue um detalhamento sucinto sobre as duas TS a serem reaplicadas.

\subsection{Primeira Tecnologia Social: Transformando Realidades por Meio da Mobilização e Organização Comunitária}

A busca pela conquista dos direitos de cidadania e moradia proposta pela INTERAÇÃO por meio da primeira TS trabalha com a metodologia aplicada por intermédio do tripé: poupança comunitária, autorrecenseamento e intercâmbio de experiências.

Chama-se de autorrecenseamento o censo feito pelos próprios moradores de uma área que inclui desde informações típicas de cadastros municipais, como dados demográficos e perfil socioeconômico, até quaisquer outros elementos que a comunidade julga pertinente, como a quantidade de pessoas com deficiência, gestantes, crianças desnutridas, entre outros. O intuito é fazer uma verificação cuidadosa, completa e detalhada, cujas informações possam vir a ser sistematizadas. A aplicação da técnica extrapola a simples obtenção da informação, afinal “[ [...] há também um aprendizado relacionado ao questionamento, no qual a comunidade envolvida tem a oportunidade de discutir e pensar sobre seu território. Esse não é um processo de aprendizado tradicional $[\ldots]$ ”.. (INTERAÇÃO, 2014, s/p).

A segunda técnica que compõe o tripé da metodologia em questão é a poupança comunitária. Constitui um fundo formado e mantido pelos moradores, organizados em grupos de poupança. Observa-se que a iniciativa supera o âmbito financeiro, já que, segundo a Fundação Banco do Brasil (2012), "os poupadores passam a antecipar dificuldades e oportunidades bem como 
discutir questões de gastos e gestão de recursos, que frequentemente evoluem para assuntos como planejamento, estratégias de atuação e negociações [ [...]”.

Por último, não menos importante, o intercâmbio se apresenta como maneira eficiente de disseminar as metodologias e as práticas no que diz respeito à TS, dado que há intensa troca de informações e experiências entre os sujeitos. Realizado entre países, cidades ou mesmo entre comunidades num dado município, a ideia do intercâmbio é fortalecer o conhecimento sobre o próprio ambiente, reconhecer desafios comuns, buscar criativas soluções para as demandas coletivas e, naturalmente, estabelecer uma rede de contatos.

\subsection{Segunda Tecnologia Social: Joias Sustentáveis}

Conforme mencionado previamente, faz-se a reaplicação da segunda TS após escolha da própria comunidade. No caso Candelária, Joias Sustentáveis foi eleita como iniciativa do Instituto Redecriar, que visa à sustentabilidade, à geração de renda e à autonomia para a coletividade. A partir do reaproveitamento de embalagens plásticas, produzem-se, artesanalmente, peças cujo “[...] processo de produção busca o equilíbrio entre as dimensões ambiental, social e econômica. A dimensão ambiental se expressa na separação e reaproveitamento de resíduos domésticos. A dimensão social se revela na promoção da participação e da organização comunitária. E a dimensão econômica se manifesta na experiência de geração de trabalho e renda" (INTERAÇÃO, 2014, s/p).

Trabalha-se com três módulos, contemplando teoria e prática, fundamentada nos eixos: descobrir, cuidar e envolver. Descobrir as potencialidades individuais e a capacidade de organização do coletivo; preservar os espaços como meio de cuidar do planeta; e envolver a comunidade multiplicando o aprendizado.

\section{METODOLOGIA}

Analisando a origem e a evolução do vocábulo método, encontra-se o significado como sendo o caminho para chegar a um fim, o que leva ao entendimento de método científico como caminho para chegar à verdade em ciência (GIL, 2008).

Primeiramente, para a construção do presente artigo, fez-se uma pesquisa bibliográfica sobre Tecnologia Social desde março do ano corrente, que ofereceu embasamento para a reflexão apresentada. Gil (2008) defende que a pesquisa bibliográfica é desenvolvida a partir de um material já elaborado, constituído principalmente de livros e artigos científicos, permitindo ao investigador a cobertura de uma gama de fenômenos muito mais ampla.

No intento de complementar o referencial teórico, a pesquisa documental permitiu conhecer mais sobre o projeto Moradia Urbana com Tecnologia Social; atas, relatórios e depoimentos foram acessados, a fim de elucidar questões que afloraram no decorrer da pesquisa.

De natureza qualitativa, utilizou-se para coleta de dados entrevistas semiestruturadas com representantes do Grupo de Acompanhamento Local (composto pelas instituições: Banco do Brasil, Prefeitura de Volta Redonda, INTERAÇÃO, PROATEC e Redecriar), aprofundando conhecimentos sobre TS, especificamente a operacionalização no caso do Conjunto Residencial Candelária. Por fim, moradores do Conjunto foram entrevistados com o propósito de se identificarem traços emancipatórios nos discursos proferidos. 


\section{A PESQUISA}

Ao sul do estado do Rio de Janeiro, com aproximadamente 260.000 habitantes (IBGE, 2016), Volta Redonda se destaca nacionalmente como "Cidade do Aço", por abrigar a Companhia Siderúrgica Nacional (CSN). Localizado no bairro Candelária, um dos noventa bairros dessa cidade, o Conjunto Residencial Candelária é um empreendimento habitacional do Minha Casa, Minha Vida, pilar fundamental da Política Nacional de Habitação. Caracteriza-se pelo agrupamento de nove blocos de três andares, com quatro apartamentos em cada andar, abrigando um total de 144 famílias em situação de vulnerabilidade econômica. Tal empreendimento, financiado pelo Banco do Brasil, faz parte de um grupo de unidades habitacionais em todo o país escolhidas para receberem o projeto Moradia Urbana com Tecnologia Social

Com objetivo de se acessar as narrativas que pudessem reconstruir toda a experiência vivenciada pela comunidade do Conjunto Residencial Candelária, utilizaram-se entrevistas semiestruturadas com quatro representantes do Grupo de Acompanhamento Local. Nessa primeira etapa, a coleta de dados foi realizada majoritariamente por videoconferências ocorridas no mês de maio (2017); com duração média de quarenta e cinco minutos, as entrevistas abordavam o processo de instauração das Tecnologias Sociais, bem como o desenvolvimento do trabalho, como profissionais responsáveis pela viabilização do projeto MUTS.

No segundo momento, agendou-se a maioria dos encontros com os moradores para o mês de junho (2017), estando-se duas vezes na Comunidade Candelária, em seus respectivos locais de residência fixa. Em cada visita, verificou-se a possibilidade de fazer uma entrevista, utilizando um gravador para posterior transcrição, resguardando a identidade dos colaboradores da pesquisa. Com duração de aproximadamente vinte minutos, duas perguntas foram feitas aos entrevistados: (1) “O que mudou na vivência em comunidade após as experiências de Tecnologia Social?” e; (2) “Como as experiências do Censo e das Joias Sustentáveis afetaram a sua vida?”.

Considerando a extensa possibilidade de reflexões a partir dos resultados obtidos, esse trabalho enfatiza uma das questões tida como primordial: identificar traços de emancipação social nas narrativas dos moradores. A amostra selecionada contém quatro moradores envolvidos ativamente na reaplicação das Tecnologias Transformando realidades por meio da mobilização social e/ou das Joias Sustentáveis.

\section{RESULTADOS E DISCUSSÕES: A EXPERIÊNCIA NO CONJUNTO RESIDENCIAL CANDELÁRIA}

A INTERAÇÃO contribuiu para o desenvolvimento do escopo geral do projeto e mais destacadamente da primeira TS, o Censo, ou Autorrecenseamento. Para pôr em prática a segunda TS, eleita em assembleia pelos moradores do Conjunto, a Redecriar se fez presente com as Joias Sustentáveis. A FBB fez a contratação (mediante edital de licitação) de uma terceira instituição, a PROATEC, com atuação relacionada às temáticas do projeto MUTS com propósito de viabilizar as reaplicações. O poder público foi representado pela Prefeitura Municipal de Volta Redonda, principalmente por meio da Secretaria Municipal de Ação Comunitária (SMAC).

Paralelo à entrega das chaves do Conjunto Residencial, acontecia a capacitação presencial técnica da Instituição Local, no caso a PROATEC, dirigida pela INTERAÇÃO. Utilizando uma plataforma digital, parte da capacitação para atuação no projeto também acontecia por meio de vídeos e textos. 


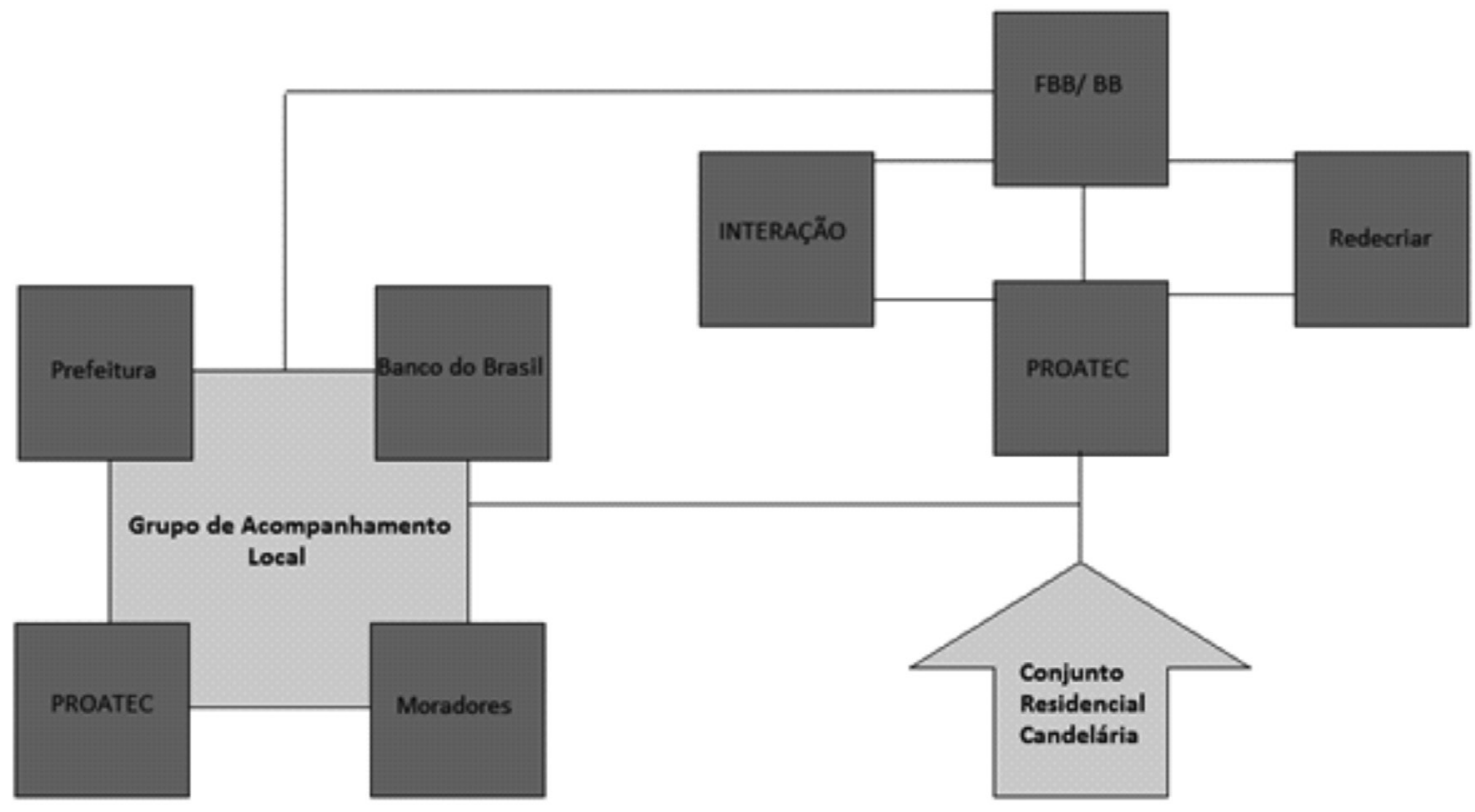

Fonte: Elaborada pelos autores com base em INTERAÇÃO (2014).

Após a realização do workshop de capacitação e sinalização do início dos trabalhos pela FBB, a PROATEC realizou um trabalho de identificar, contactar e articular os atores institucionais locais na intenção de propor uma cooperação mútua, integrando os trabalhos.

O primeiro produto do início da relação entre os atores locais foi um Plano de Trabalho proposto, no qual se compreendeu o trabalho a partir de um detalhamento das ações que seriam empreendidas na comunidade. O documento apresenta justificativa, público-alvo, objetivos, atividades, monitoramento, dimensionamento de equipe e recursos e, claro, cronograma.

Antes da realização da primeira assembleia, a INTERAÇÃO visitou o empreendimento da Candelária no intuito de apoiar e acompanhar o início dos trabalhos no que diz respeito à articulação institucional, à articulação com lideranças e representantes, à elaboração do Plano de Trabalho e à mobilização para assembleia e à preparação da reaplicação da primeira TS.

A primeira assembleia foi realizada no espaço comum do empreendimento, sendo a atividade de lançamento do projeto para a totalidade dos moradores do Conjunto. Foi convocada pelos próprios condôminos com mecanismos próprios de mobilização, como a abordagem pessoal de apartamento por apartamento. Entre as principais pautas, a equipe da PROATEC foi apresentada como quem acompanharia os trabalhos até o final, o projeto foi explicado de forma clara e sucinta com foco nos objetivos e na relevância, a fim de sensibilizar o grupo e, também, definiram-se os voluntários da reaplicação da primeira TS, o autorrecenseamento. Essa operacionalização teve início em meados de outubro de 2015.

Foi necessária uma reunião para detalhamento da primeira TS, cujas dúvidas foram esclarecidas e fez-se a identificação dos moradores voluntários, um número baixo, inferior a dez. Após a capacitação dos voluntários, o autorrecenseamento foi realizado com uma conversão de aproximadamente $70 \%$ de questionários respondidos com dados sobre o perfil dos moradores e a percepção destes sobre o local onde vivem. Foram pautas principais na segunda assembleia: devolutiva dos resultados do censo, escolha da segunda TS a ser implementada no Conjunto e mobilização para atividade de educação financeira. 
Em maio de 2016, após a explicação das quatro opções de Tecnologias Sociais para segunda parte do projeto MUTS, a comunidade escolheu pelas Joias Sustentáveis. Apesar da falta de quórum em assembleia (estima-se que menos de quinze condôminos estavam presentes), as organizações locais prontamente entraram em contato com a Redecriar, instituição responsável pela segunda TS, iniciando um novo plano de trabalho contendo uma descrição das atividades que viriam a ser desempenhadas.

De junho a outubro de 2016, aconteceu a reaplicação da segunda TS. Duas capacitações foram realizadas antes do início da produção das Joias Sustentáveis. A matéria-prima do trabalho artesanal tem origem, principalmente, nos materiais plásticos descartados por todos. $\mathrm{O}$ beneficiamento das embalagens de shampoos, detergentes, garrafas PET, etc., é um exemplo que, aliado a outros elementos (miçangas e pedrarias), constituem o produto final. Foram reforçados os princípios de separação de resíduos domésticos, comercialização e fortalecimento da cooperação e perspectivas de futuro.

\subsection{NA PERsPeCtiVA DO GRUPO DE ACOMPANHAMENTO LOCAL}

O projeto Moradia Urbana com Tecnologia Social abrange 124 empreendimentos do Minha Casa, Minha vida, sendo o Conjunto Residencial Candelária a primeira experiência da história do projeto. Entende-se que é válido destacar que, como toda proposta pioneira, foi passível de muitos erros. De acordo com um dos representantes do Grupo de Acompanhamento Local, a replicabilidade é um desafio enorme porque, apesar das especificidades de cada comunidade, é necessário ter uma experiência de trabalho semelhante para tentar minimizar os problemas, construindo uma experiência exitosa.

Pode-se notar que famílias de várias partes da cidade foram levadas para o Residencial Candelária e que tinham uma série de problemas de relacionamento no Conjunto, alguns fáceis de serem resolvidos, outros nem tanto. Existe certa dificuldade, por exemplo, de lidar com as regras do condomínio, dado que muitos moradores, pela primeira vez, foram condicionados a conviver em área coletiva, comum a outras pessoas.

O Conjunto Residencial é composto majoritariamente por mulheres, um número significativo de famílias só tem a mulher como chefe. Tem-se um perfil de renda muito baixo, até porque muitos moradores não trabalham.

Como já discutido, a metodologia da INTERAÇÃO prevê a utilização dos três dispositivos (autorrecenseamento, poupança comunitária e intercâmbio) entretanto, por demanda da comunidade, só o censo foi colocado em prática. Na metodologia pura, cada formulário do Censo é dialogado com os moradores, mas para o projeto da FBB se criou um formulário fixo, permitindo a padronização da coleta em todos os empreendimentos, inclusive no Candelária.

Osvoluntários dacomunidadeforam treinados econseguiram realizaroautorrecenseamento no empreendimento de forma censitária. Além do perfil socioeconômico dos moradores, foi possível fazer uma avaliação do empreendimento, identificando os problemas existentes nas unidades habitacionais. O censo proporcionou a obtenção de um diagnóstico bastante completo do perfil dos moradores, das suas demandas e dos serviços necessários ao bairro; organizou representantes dos moradores; e identificou quais as TS os moradores gostariam de implantar no empreendimento. Duas tecnologias foram mais requeridas e o resultado foi apresentado na segunda assembleia 
realizada com os moradores para definir a TS a ser reaplicada no empreendimento. Cogita-se que, pela maioria dos presentes nas assembleias serem mulheres e a falta de emprego formal ser uma característica do Conjunto, as Joias Sustentáveis viriam na junção do “útil ao agradável”.

A implementação da segunda TS teve metodologia aplicada pelo Instituto Redecriar para um grupo de moradores que se interessaram pela atividade. Na primeira capacitação um número razoável de participantes esteve presente, em torno de trinta pessoas, incluindo jovens. Na segunda capacitação, que trabalhou a qualidade das peças das joias, o número foi reduzido para dez pessoas. Alguns moradores ficaram engajados e no final da capacitação formaram um grupo produtivo de quatro mulheres que deram continuidade a esta TS.

O projeto durou aproximadamente doze meses, acompanhando as duas tecnologias reaplicadas, mas é necessário frisar que, antes e depois das replicações, as instituições também atuaram. Nesse tempo de um ano, o acompanhamento mensal se deu por meio de reuniões com os moradores, representantes dos moradores e Grupo de Acompanhamento Local (composto basicamente por pessoas do Banco do Brasil, Prefeitura, INTERAÇÃO, Redecriar e PROATEC).

Ao encerrarem os trabalhos, o Grupo de Acompanhamento realizou duas reuniões no Banco do Brasil, a fim de discutir os impactos da experiência e traçar estratégias para impulsionar a continuidade da TS.

A maioria dos integrantes do Grupo de Acompanhamento Local sentiu-se bem recebida pela comunidade, notando um maior interesse por parte dos moradores no início da proposta de intervenção. Em termos gerenciais, acreditam que as TS foram bem implementadas na medida do possível; existia uma cartilha com todas as atividades que eram pra ser realizadas e a PROATEC seguiu todos os caminhos, entretanto o sentimento é de que só aquilo não foi suficiente em termos de empoderamento e organização comunitária.

Por ter sido a primeira experiência do projeto MUTS, atualmente muitos processos são realizados de forma diferente do que foi no Candelária. Para garantir o maior apoio possível, o número de visitas feitas aos Conjuntos, por exemplo, é maior, além do que as atividades de campo ficam mais completas.

\subsection{NA PERSPECTIVA DOS MORADORES}

Como mencionado anteriormente, na entrevista com os moradores do Residencial Candelária foram feitas duas perguntas reconstruindo a experiência da TS na comunidade com o propósito de se identificar, ou não, traços emancipatórios nos discursos dos sujeitos. Nos parágrafos a seguir, faz-se uma síntese das opiniões expressas ao se questionar: 1. "O que mudou na vivência em comunidade no Conjunto Residencial Candelária após as experiências de Tecnologia Social?” e; 2.“Como as experiências do Censo e das Jóias Sustentáveis afetaram a sua vida?”.

Em outubro de 2016, nas últimas semanas de finalização do projeto, restavam poucos moradores na construção da TS na comunidade. Tais condôminos relatam que a quantidade de sujeitos do Conjunto que participava das atividades propostas foi diminuindo gradativamente ao ponto de, na última fase do projeto, apenas três mulheres da comunidade se debruçarem sobre a confecção das joias.

No início do projeto, os materiais eram trazidos prontos para o uso e uma grande quantidade ficou disponível, não foram simplesmente dados, eles tiveram preço e foram pagos pelas próprias artesãs. Atualmente elas pegam os materiais diretamente do lixo para produzirem 
peças; o beneficiamento da matéria-prima envolve corte, queima e furagem do material. Ainda que em pequena escala, teve uma mudança de consciência e algumas pessoas da comunidade passaram a não descartar embalagens que poderiam ser utilizadas como matéria-prima na confecção dos trabalhos sustentáveis.

Pouco tempo depois, em vez de produzirem no espaço comum do empreendimento, deslocaram a produção para o CRAS do Candelária, que já contava com a presença de outras mulheres com trabalhos manuais. A impressão delas é de que as pessoas num geral não conhecem o produto, por isso não há venda em alta quantidade. Não encontraram na região ninguém que trabalhasse o conceito de Joias Sustentáveis e gostariam que, de certa forma, isso fosse reconhecido na cidade, despertando o interesse e a consciência para o complexo trabalho desenvolvido. Dizem ainda ser necessário o envolvimento de outras pessoas como uma forma de "apadrinhá-los", almejando, no melhor dos cenários, uma cooperativa cuja bandeira seria a da produção sustentável.

Por algum problema que não conseguiram explicar, as artesãs não expuseram os produtos durante muito tempo no espaço do Mercado Popular cedido pela prefeitura. Elas ainda tentam alternativas de locais onde as peças possam ser notadas e comercializadas. As universidades foram pensadas como possibilidades para promoverem esse tipo de trabalho, afinal há interesse acadêmico na temática pouco debatida das Tecnologias Sociais. Diversos cursos poderiam auxiliar no processo de produção e comercialização das joias.

Apesar de momentos enriquecedores de diálogos, partilhas e interação, os moradores do Conjunto não relatam uma mudança substancial na forma como se dá a vivência em toda a comunidade no Candelária. Haveria potencial de impacto muito maior se as pessoas se envolvessem verdadeiramente com a proposta.

Ao serem questionados em nível individual sobre o modo como foram afetados em suas vidas particulares a partir da experiência da TS, as respostas foram mais motivadoras. Nos relatos constam que, quem nunca antes havia desenvolvido um trabalho artesanal, hoje já incorpora a produção na rotina diária; além do consumo do tempo como terapia, enxergam no artesanato a possibilidade real de geração de renda, trabalhando em casa com aquilo que gostam.

O projeto despertou o interesse pela produção de novas coisas. Os conhecimentos adquiridos com relação à consciência ambiental e às novas práticas sustentáveis as levaram a repensar a forma como lidam com os rejeitos da própria casa. Conforme o interesse crescia, maior e mais diversificada era a produção, indo além de apenas joias.

Existem muitas dificuldades na continuação da proposta da TS Joias Sustentáveis por limitação de recursos financeiros, mobilização popular, apoio de instituições e espaço para comercialização dos produtos. Entretanto, todos entrevistados manifestam vontade de continuar na atividade.

Das três mulheres envolvidas na perpetuação da TS Joias Sustentáveis, uma não é do Conjunto Residencial, mas sim do bairro Candelária. Logo, o projeto também afetou, em alguma dimensão, a comunidade do bairro Candelária, transpondo os muros do Conjunto Residencial.

\section{CONCLUSÃO}

A Tecnologia Social, vinculada à Teoria Crítica da Tecnologia, apresenta interessantes traços emancipadores. Feenberg (2004, p. 2-3) defende que “[ $[\ldots]$ onde quer que as relações sociais 
sejam mediadas pela tecnologia moderna, é possível introduzir controles mais democráticos e reformular a tecnologia a fim de acolher maiores inputs de perícia e iniciativa”. Experiências de TS, como as investigadas no caso Candelária, carregam como fundamentos tais controles democráticos. Ao afirmar que "[ $\ldots .$.$] a tecnologia media e molda os grupos sociais que, por sua vez, mediam$ e moldam a tecnologia”, Feenberg (2009, p. 115) lança bases para se presumir uma sociedade com diferentes "molduras". Como sustenta Dagnino et al. (2004), “[ ... $]$ segundo a teoria crítica, a tecnologia existente 'emolduraria' não apenas um estilo de vida, mas muitos possíveis estilos diferentes, cada um refletindo diferentes escolhas de design e diferentes extensões da mediação tecnológica”. Segundo Freitas e Segatto (2014, p. 308), “as tecnologias não seriam meros artefatos ou ferramentas, dispostos aleatoriamente a serviço do homem, em uma relação reducionista, mas, ao contrário, serviriam como suportes a estilos de vida”.

A investigação das reaplicações de TS no Conjunto Residencial permitiu, além da análise conclusiva relacionada à emancipação social, identificar-se alguns pontos específicos dessa experiência e relevantes de serem trazidos: apesar dos diálogos e interações, os moradores do Conjunto não relatam uma mudança substancial na forma como se dá a vivência em comunidade após as experiências das TS, entretanto indivíduos que participaram ativamente das propostas sinalizam consideráveis transformações pessoais; o autorrecenseamento não se fez totalmente inteligível aos moradores; a comunidade não apresentou suficiente mobilização social, sendo difícil a presença maciça dos condôminos, esvaziando os espaços propostos; as condições sociais e, sim, políticas afetaram diretamente o andamento das experiências; o processo de reflexão poderia ter acontecido em maior escala; a grande maioria era de as mulheres, sendo que três delas permanecem na atividade das joias sustentáveis até o presente momento; as relações institucionais, aparentemente, funcionaram de modo coeso durante as replicações; outras possibilidades de continuidade ainda são pensadas pelas poucas pessoas mais envolvidas no caso do Conjunto Residencial Candelária.

De modo mais perceptível, na reaplicação da segunda TS, pode-se inferir a partir das respostas obtidas nas entrevistas que as mulheres estavam presentes conscientemente em todo o processo de produção das joias, da seleção da matéria-prima à comercialização do produto. Existe ali o sentimento de autoria, de pertencimento ao artesanato confeccionado. Todos entrevistados que se envolveram na produção das joias expressaram seu trabalho como uma verdadeira confirmação de si, significante de toda uma criatividade produtiva.

A ocupação na produção das joias ultrapassa a finalidade estritamente econômica, dando espaço ao reconhecimento das singularidades humanas. Traços emancipatórios foram expressados de diferentes formas; nas declarações orgulhosas pelas criações artísticas, na satisfação pelo trabalho autônomo aprendido e desenvolvido na própria comunidade, no reconhecimento comunitário, no estabelecimento de novas redes sociais e no estímulo para ampliação dos conhecimentos.

Vale ressaltar que há uma relativa independência do mercado na produção das joias, haja vista que a matéria-prima utilizada em maior quantidade é encontrada nos materiais descartados pela própria comunidade, permitindo algum grau de autossuficiência. Foge-se à lógica organizacional centrada no mercado, gerida sob uma ótica instrumental que, muitas vezes, despersonaliza o indivíduo. O custo dessa produção passa a ser mínimo, com valor financeiro baixo, entretanto valor social inestimável. Há ricas histórias por trás da produção, mulheres, chefes de família, que geram renda, além de outras benesses, a partir de resíduos dercartados pela comunidade.

A realização do presente trabalho apresentou dificuldades as quais se citam, entre as principais, a falta de informação disponível na rede sobre a experiência das replicações das TS, 
a burocracia no acesso a documentos, as negativas de alguns moradores que se recusaram a responder perguntas e a ausência/demora de respostas por parte de alguns representantes do Grupo de Acompanhamento Local.

Apresentou-se aqui uma reflexão preliminar sobre a Tecnologia Social em interface com a emancipação social. Há intenção de dar continuidade aos estudos sobre o tema até mesmo por, no decorrer da investigação, ter-se dado conta de que o conteúdo apresenta extensas possibilidades a serem exploradas. Justifica-se uma possível agenda de pesquisa pela amplitude do tema e pela perspectiva de construção interdisciplinar no assunto, criando subsídios para outras reflexões acerca das Tecnologias Sociais.

\section{REFERÊNCIAS}

CUPANI, A. A tecnologia como problema filosófico: três enfoques. Scientiae Studia, São Paulo, v. 2, n. 4, p. 493-518, dec. 2004.

DAGNINO, R; BRANDÃO, F. C.; NOVAES, H. T. Sobre o marco analítico-conceitual da Tecnologia Social. In: FBB. Tecnologia Social: uma estratégia para o desenvolvimento. Rio de Janeiro: FBB, 2004. 15-64 p.

FEEnBERG, A. Critical Theory of Technology. New York and Oxford, Oxford University Press, 1991.

FEEnBERG, A. Teoria Crítica da tecnologia. Piracicaba: Unimep, 2004.

FEENBERG, A. Cinco paradoxos da tecnologia e da política de desenvolvimento. In: OTERLOO, A. et al. Tecnologias Sociais: caminhos para a sustentabilidade. Brasília: s.n., 2009. 99-116 p .

GIL, A. C. Métodos e Técnicas de Pesquisa Social. São Paulo: Editora Atlas, 2008.

FREITAS, C. C. G.; SEGATTO, A. P. Ciência, tecnologia e sociedade pelo olhar da Tecnologia Social: um estudo a partir da Teoria Crítica da Tecnologia. Cad. EBAPE.BR, Rio de Janeiro , v. 12, n. 2, p. 302-320, June 2014.

\section{GUERREIRO RAMOS, A. A nova ciência das organizações. São Paulo: FGV, 1989.}

IBGE. Disponível em: <http://cidades.ibge.gov.br/xtras>. Acesso em: 01 de junho de 2017.

MARX, K. Manuscritos Econômicos Filosóficos. São Paulo: Ática, 1983.

O PROJETO. MORADIA URBANA COM TECNOLOGIA SOCIAL. Disponível em: <https:// moradiaurbanats.org.br/>. Acesso em: 20 de maio de 2017.

PINTO, A. V. O conceito de tecnologia. Rio de Janeiro: Contraponto, 2005.

PROJETO MORADIA URBANA COM TECNOLOGIA SOCIAL. Disponível em: < http:// redeinteracao. org.br/?page_id=3022>. Acesso em: 13 de maio de 2017.

TECNOLOGIA SOCIAL. FUNDAÇÃO BANCO DO BRASIL. Disponível em: <http:// tecnologiasocial.fbb.org.br/tecnologiasocial/o-que-e/tecnologia-social/o-que-e-tecnologiasocial.htm>. Acesso em: 07 de maio de 2017. 